\title{
Uso da Acupuntura em Crianças com Sintomatologia de Estresse: Um Estudo Exploratório
}

\author{
Celia Vectore" \& Cínthia Pereira Alves \\ Universidade Federal de Uberlândia, Minas Gerais, Brasil
}

\begin{abstract}
RESUMO
Este estudo objetivou avaliar o uso da acupuntura na sintomatologia indicativa de estresse infantil. Foram utilizados a Escala de Stress Infantil e o aparelho de avaliação energética Ryodoraku. Participaram seis crianças com idade entre seis e sete anos. A intervenção consistiu em doze atendimentos para cada participante. Os resultados obtidos indicam que o tratamento propiciou uma harmonização do nível energético, com o potencial de contribuir para minimizar os sintomas de estresse, como medo, nervosismo, ato de roer unhas, insônia e inquietação. Contudo, novos estudos devem ser empreendidos para avaliação efetiva da técnica. Destaca-se a importante interface entre conhecimentos da Psicologia e Acupuntura, que podem ser agregados para o devido enfrentamento da problemática.
\end{abstract}

Palavras-chave: Medicina Tradicional Chinesa; acupuntura; estresse infantil.

\section{ABSTRACT \\ Use of Acupuncture in Children with Symptoms of Stress: An Exploratory Study}

This study aimed to evaluate the use of acupuncture on symptoms indicative of anxiety in children. The instruments used were the Child Stress Scale and the Ryodoraku method for energy assessment. Six children participated in this research, aged between six and seven years old. The intervention consisted of twelve sessions for each child. The results indicate that the treatment provided an energy harmony, with potential to reduce the symptoms of stress, such as fear, nervousness, act of nail biting, insomnia and restlessness. However, further studies should be undertaken for effective evaluation of the technique. The study highlights the important interface between psychology and acupuncture, which can be used together to face the problem.

Keywords: Traditional Chinese Medicine; Acupuncture; Child stress.

O ritmo acelerado da vida em sociedades, as novas configurações familiares, a violência doméstica, entre outros fatores contribuíram para o realce dado a temas como ansiedade e estresse infantil. Em escala mundial, cerca de $10 \%$ das crianças e adolescentes sofrem de transtornos ansiosos (Asbahr, 2004; Farrow, Haycraft, \& Meyer, 2009; Silva \& Figueiredo, 2005; Zumstein, 2009).

Entretanto, de acordo com a American Psychiatric Association (APA) (2002), a ansiedade pode ser considerada uma ocorrência comum na infância, devido a tratar-se de um tipo de reação emitida pela criança diante de diversos acontecimentos, que permeiam o seu contexto. Para tanto, a referida associação apre- senta a seção Ansiedade subdividindo-a entre Transtornos de Ansiedade e Transtornos de Estresse, o que sugere uma proximidade conceitual desses constructos, parecendo diferir somente na forma de manifestação sintomática.

Pais-Ribeiro, Honrado e Leal (2004) confirmaram essa análise ao avaliar a Depression Anxiety Stress Scale (Escala de Ansiedade, Depressão e Stress EADS) de Lovibond e Lovibond (1995). Aqueles constataram que essa escala admite que as diferenças entre depressão, ansiedade e estresse são unicamente dimensionais e não categoriais, ou seja, o que define se uma pessoa está sofrendo de depressão, estresse ou ansiedade é o grau de intensidade com que os sintomas se manifestam nela.

\footnotetext{
*Endereço para correspondência: Celia Vectore -pgpsi@fapsi.ufu.br; vectore@ufu.br
} 
De modo geral, tem-se que as situações deflagradoras de ansiedade não necessariamente acompanham um perigo real, porém a pessoa não é capaz de tal percepção e passa a manifestar sensações de desconfortos corporais, como fraqueza, boca seca, sudorese, sensação de aperto no peito e garganta, palpitação, dentre outros (Assumpção \& Rech, 2006). Tal sintomatologia também está presente em crianças que sofrem de estresse, conforme sugerem Lipp e Lucarelli (2005).

Lipp (2000) e Simmons (2000) apontam que o estresse é uma reação de adaptação do organismo a agentes estressores negativos e/ou positivos, na tentativa de restabelecer o seu equilíbrio. Normalmente, há a presença de sensações físicas e mentais, como o aumento da transpiração, a aceleração dos batimentos cardíacos e o aumento da atenção e do estado de alerta, dentre outras reações (Assis, Ximenes, Avanci, \& Pesce, 2007).

A identificação acurada dos sintomas de estresse é desejável devido ao seu potencial deletério, ao contribuir com possíveis comprometimentos na adolescência e vida adulta (Assis et al., 2007). Portanto, a sua prevenção e tratamento se constituem em fatores passíveis de um desenvolvimento saudável, conforme indica Muzzolon (2008).

Em contexto brasileiro, algumas tentativas têm sido empreendidas para a obtenção de instrumentos que possam identificar e intervir em quadros de estresse em crianças pequenas, menores de seis anos (Horta, 2007; Zumstein, 2009). Contudo, a Escala de Stress Infantil (Lipp \& Lucarelli, 2005) é o instrumento disponível, com características psicométricas adequadas para a avaliação do estresse em crianças a partir dos seis anos.

A escala supracitada aponta a existência de quatro fases de reação do organismo ao estresse. São elas: fase de alerta, em que o organismo é acometido por um agente estressor e prepara-se para a ação, por meio de reações fisiológicas, como tensão muscular e aumento da frequência cardiorrespiratória. Se o estressor continua atuante, o organismo passa para a fase de resistência, caracterizada por uma leve diminuição das reações da fase anterior, porém acompanhada de um gasto energético excessivo desviado de outras funções vitais. A fase seguinte é a quase-exaustão, na qual a tensão ultrapassa o limite de controle do organismo e acarreta uma baixa no sistema imunológico e labilidade emocional. A última fase é a exaustão, caracterizada pelo agravamento dos sintomas e pelo desgaste do organismo, podendo induzi-lo a doenças graves e fatais (Lipp \& Lucarelli, 2005).

O reconhecimento de quadros de estresse em crianças e o adequado manejo têm se constituído em uma tarefa árdua para os psicólogos que lidam diretamente com o público infantil, nos mais diferentes contextos. Entre as abordagens disponíveis ao profissional da Psicologia tem-se que, a comumente utilizada no manejo do estresse é a terapia cognitivo-comportamental, contudo, estudos realizados com a utilização da acupuntura em adultos têm evidenciado a sua pertinência (Silva, 2010; Evans, 2012).

Nesse sentido, uma das possibilidades para a intervenção em quadros de estresse infantil pode ser o uso da acupuntura, uma das abordagens da Medicina Tradicional Chinesa (MTC) que vem apresentando um crescente número de publicações científicas nacionais e internacionais (Cabioglu, Ergene, \& Tan, 2007; Silva, 2010; Evans, 2012). Em contexto brasileiro, o trabalho de Doria, Lipp e Silva (2012) atestou a adequação da acupuntura na sintomatologia do estresse. Contudo, é importante destacar que os estudos avaliando o uso da acupuntura em crianças são ainda escassos, em termos mundiais. Jindal, Ge e Mansky (2008), em uma revisão acerca da eficácia e segurança da acupuntura com a população infantil, observaram a sua indicação para náuseas e vômitos induzidos pela quimioterapia, rinite alérgica sazonal e enurese noturna. Ressaltaram se tratar de uma modalidade aparentemente segura para o tratamento de pacientes pediátricos com base nos dados analisados.

Gold, Nicolaou, Belmont, Katz, Benaron e Yu (2009), revisaram estudos de acupuntura na pediatria e concluíram sobre a necessidade de um maior número de estudos, a fim de permitir a incorporação de tais tratamentos na infância. Vale destacar que não foi localizado nenhum estudo específico abordando o uso da acupuntura em quadros de estresse infantil.

Embora não seja o propósito do presente relato explicitar o funcionamento da acupuntura, sugerindo-se para tanto a leitura de trabalhos como os de Campiglia (2004), Hicks, Hicks e Mole (2007), Maciocia (2007b) e Ross (2003), algumas noções serão apresentadas devido ao pouco conhecimento de tal instrumento pelo psicólogo, já que são ainda escassas as contribuições em território nacional (Doria, 2010; Silva, 2010; Vectore, 2005).

Em termos genéricos, a acupuntura visa prevenir e tratar doenças que acometem o organismo em desequilíbrio. A técnica da acupuntura fundamenta-se 
principalmente na filosofia taoista, a partir da concepção do ser humano como uma unidade interligada a todos os outros fenômenos no universo. $\mathrm{O}$ qi, que pode ser entendido como energia, é responsável pela união e manifestação de todos os eventos, encontrando-se todos os fenômenos da natureza imersos no qi (Hicks et al., 2007).

Para a Medicina Tradicional Chinesa (MTC), é impossível separar a energia mental da energia física, pois ambas são apenas dois aspectos diferentes do mesmo qi. Campiglia (2004) enfatizou que o qi é o fator constituinte do corpo humano, circulando pelos meridianos de acupuntura ou canais de energia. Segundo Yamamura (1993), o qi é a forma imaterial que promove a atividade e o dinamismo dos seres, e manifesta-se sob a forma de yin e yang, que são duas forças contrárias, porém complementares e indissociáveis. Esse autor expôs que a energia yin produz o frio, o retraimento, a descida, o repouso, a escuridão e a diminuição de todas as atividades. A energia yang produz o calor, a expansão, a explosão, a ascensão, a claridade e o aumento de todas as atividades.

A acupuntura foi desenvolvida com o objetivo de preservar o estado de equilíbrio interno das energias (yin e yang), antes da instalação da patologia. Dessa forma, o diagnóstico e o tratamento pela técnica são voltados para a saúde do indivíduo e não apenas para os sintomas apresentados por ele. Nesse contexto, tem-se que a essência da medicina chinesa está na ideia de que tudo no universo é governado por yin e yang e pelos Cinco Elementos. Os Cinco Elementos são Madeira, Fogo, Terra, Metal e Água, sendo que o elemento Fogo se divide em Fogo Imperial e Fogo Ministerial, e estão presentes em todos os seres. Cada elemento possui uma característica específica e formas diferentes de manifestação (Hicks et al., 2007).

De acordo com Maciocia (2007a), os meridianos (ou canais de energia) circundam todo o corpo, fazendo caminhos em direção ascendente e descendente, passando no interior do corpo e se conectando aos órgãos e às articulações, e se ligando aos quatro membros. É pelos canais que o qi circula e o yin e yang são regulados, mantendo o equilíbrio das funções do organismo. Para a MTC há doze meridianos energéticos no corpo humano, por onde tal energia circula. Esses meridianos são bilaterais e possuem os acupuntos, que são pontos que devem ser estimulados por agulhas ou outros materiais não invasivos, como sementes, stiper - que será melhor detalhado no correr do texto - e outros.
Os doze meridianos principais relacionam-se aos seis órgãos e às seis vísceras presentes nos Cinco Elementos, sendo: Pulmão (P), Intestino Grosso (IG), Estômago (E), Baço-Pâncreas (BP), Coração (C), Intestino Delgado (ID), Bexiga (B), Rim (R), Pericárdio (Pe), Triplo Aquecedor (TA), Vesícula Biliar (VB) e Fígado (F). Além dos doze meridianos principais, existem dois meridianos extraordinários, o Vaso Concepção (VC) e o Vaso Governador (VG), que não se conectam diretamente a um órgão ou víscera (Maciocia, 2007a).

O mecanismo fisiológico de ação da acupuntura baseia-se em evidências científicas (Franceschini Filho, 2001 apud Vectore, 2005; Imamura, 1996; Jayasuriya, 1995). De acordo com Van de Graaff (2003), o sistema nervoso é formado por dois componentes estruturais e por um componente funcional, respectivamente: Sistema Nervoso Central (SNC), formado pelo encéfalo e medula espinal; Sistema Nervoso Periférico (SNP), formado pelos nervos cranianos, que se originam no encéfalo, e pelos nervos espinais, formados a partir da medula espinal e, Sistema Nervoso Autônomo (SNA), que possui seus centros controladores localizados no encéfalo e porções periféricas divididas em simpático e parassimpático.

As funções simpática e parassimpática atuam de forma coordenada, mantendo sempre o equilíbrio funcional. De fato, a homeostase do organismo depende dos efeitos frequentemente antagônicos, porém complementares, da inervação simpática e parassimpática. A estimulação simpática aumenta a frequência cardíaca, a glicemia, a vasoconstrição de algumas artérias, a broncodilatação e reduz as atividades urinárias e gastrointestinais. A estimulação parassimpática, responsável pela conservação e armazenamento de energia, produz a redução da frequência cardíaca, o aumento da digestão e da absorção de alimentos, e o esvaziamento urinário e intestinal (Imamura, 1996; Spence, 1991; Van de Graaff, 2003).

O SNA age de acordo com o mecanismo neuroendócrino do estresse, ficando hiperativo e perturbando diferentes órgãos, passando a manifestar sintomas clínicos concomitantes ou separadamente nos seguintes sistemas: sistema cardíaco (palpitações, taquicardia, vertigem, aperto na garganta), sistema respiratório (sufocação, apneia, hiperventilação), sistema digestivo (vômitos, diarreia, dores abdominais), sistema urinário (necessidade urgente de urinar), funções motoras (tremores, rigidez muscular), pele (arrepios, transpiração), SNC (cefaleia, reação de alarme catastrófico). A acupuntura, segundo Imamura (1996) e Jayasuriya 
(1995), age em todo o sistema nervoso do paciente, gerando o seu reequilíbrio.

Para a MTC, sintomas relacionados ao estresse são indicativos de um desequilíbrio energético, podendo ser decorrente de desarmonias nos seguintes órgãos: coração, baço-pâncreas, pulmão, rim ou fígado. Segundo essa abordagem, todos os problemas emocionais afetam o coração. Portanto, é possível afirmar que, independente do órgão responsável por deflagrar o estresse, sempre haverá o envolvimento do coração, que é considerado a morada do espírito (shen) (Campiglia, 2004; Silva, 2010).

Considerando que os pontos de acupuntura são terminações nervosas livres, cuja estimulação chega ao SNC, Imamura (1996) observou que, desde 1975, muitos pesquisadores chineses e ocidentais reconheceram o aumento da atividade neuronal advindo do estímulo gerado pela acupuntura. Nesse sentido, a autora aponta a pertinência da descoberta do médico japonês Yoshio Nakatani, que na década de 1950, medindo a eletrocondutividade da pele, identificou a existência de uma série de pontos de baixa resistência elétrica que percorrem longitudinalmente o corpo, e que tais pontos de alta condutividade elétrica estão localizados nos meridianos de acupuntura. Esse médico nomeou esses meridianos de Ryodoraku e desenvolveu um aparelho capaz de medir a energia circulante nos acupontos. Em 1958, essa técnica recebeu o nome de Acupuntura Ryodoraku.

Hugentobler (2006) e Imamura (1996), fundamentando-se nos conceitos de regulação do SNA, observaram que o Ryodoraku é um aparelho com função de diagnóstico e de eletro-estimulação. Assim, os meridianos com leitura elevada, considerados simpaticotônicos (yang), devem ser sedados e os meridianos com leitura baixa, considerados parassimpaticotônicos (yin), devem ser tonificados. Percebe-se, assim, que a parte simpática do SNA possui função semelhante à polaridade yang e a parte parassimpática possui função semelhante à polaridade yin. $\mathrm{O}$ bom funcionamento do SNA garante que o organismo mantenha a saúde, o estado homeostático. Por outro lado, o seu funcionamento anormal predispõe o organismo ao adoecimento por causas internas.

Nesse contexto, para avaliar se a quantidade de energia presente nos meridianos manifesta-se em excesso ou deficiência, causando desequilíbrios no organismo do indivíduo, pode-se utilizar o aparelho de avaliação Ryodoraku (Imamura, 1996). A acupuntura realizada nos acupontos localizados nos meridianos de energia que passam pelo corpo, denomina-se acupuntura sistêmica.

Uma forma não invasiva de tratamento com acupuntura sistêmica, em substituição ao uso das agulhas, ocorre pela utilização de pastilhas de silício, sementes de mostarda, cristais, laser, moxabustão, entre outras. A pastilha de silício, conhecida também como STIPER (Stimulation and Permanency), é uma pastilha de quartzo micronizado de Óxido de Silício, cujas micropartículas são organizadas em uma manta hipoalergênica, que possui $13 \mathrm{~mm}$ de diâmetro e $3 \mathrm{~mm}$ de espessura.

Do ponto de vista energético, as pastilhas regulam a energia corporal, tonificando o que está deficiente e sedando o que está em excesso. Do ponto de vista ocidental, as pastilhas são responsáveis pela melhora do metabolismo, relaxamento da musculatura, ativação da circulação sanguínea, aumento da imunidade, dentre outros. Tendo em vista que grande porcentagem da constituição orgânica humana é formada por silício, a pastilha de silício é um material reconhecido pelo organismo e tem a função de ordenar as suas ondas e frequências (Burigo \& Silvério-Lopes, 2010).

A acupuntura auricular ou auriculopuntura é uma forma de diagnóstico e tratamento dos desequilíbrios energéticos, por meio da estimulação de determinados pontos na orelha, considerada um microssistema. Assim, por meio da estimulação de pontos específicos (terminações nervosas periféricas) no pavilhão auricular, o estímulo chega até o córtex cerebral, que reconhece a área estimulada e, como resposta, libera neurotransmissores para a região a ser tratada (Gori \& Firenzuoli, 2007).

A auriculopuntura é uma técnica muito útil para ser usada em conjunto com a acupuntura sistêmica por prolongar os benefícios alcançados pela última. É indicada em casos de ansiedade, estresse e insônia, dentre outros (Campiglia, 2004). Na aplicação da auriculopuntura podem ser utilizadas esferas de cristal ou sementes de mostarda afixadas num pedaço de micropore, agulhas específicas e outros materiais.

Assim, o presente estudo objetivou conhecer e avaliar a adequação do uso da acupuntura na sintomatologia indicativa de estresse em crianças e, mais especificamente, comparar a sintomatologia de estresse nas crianças, antes e após a intervenção com acupuntura. Vale acrescentar que esta pesquisa se justificou pela possibilidade de preencher uma lacuna da literatura, ao avaliar os efeitos benéficos da acupuntura no manejo do estresse infantil. 


\section{MÉTODO}

\section{Participantes}

Participaram seis crianças, no estágio de vida entre seis e sete anos, oriundas de atendimentos realizados no Hospital de Clínicas da Universidade Federal de Uberlândia (UFU), no período de dezembro de 2010 a setembro de 2011. O projeto foi submetido ao Comitê de Ética e Pesquisa da UFU, estando aprovado e registrado sob o $\mathrm{n}^{\circ} 1087 / 10$.

A partir da análise dos prontuários dos pacientes com idade entre seis e sete anos atendidos no ambulatório infantil foram identificadas algumas crianças com sintomatologia indicativa de estresse, segundo observações clínicas. Das nove famílias que concordaram participar da pesquisa, apenas seis crianças prosseguiram em todas as etapas da mesma. O motivo para desistência foi impossibilidade de levar as crianças para o atendimento, pela incompatibilidade com o horário de trabalho dos pais.

\section{Instrumentos e materiais}

Com o intuito de coleta de dados foram aplicados os instrumentos e materiais abaixo descritos:

1. Anamnese, respondida pelos pais ou responsáveis, para a avaliação do histórico do nascimento e desenvolvimento da criança, capacidade de socialização, escolaridade, desempenho na escola e relacionamento familiar.

2. Escala de Stress Infantil (Lipp \& Lucarelli, 2005), que se trata de instrumento composto por 35 itens em escala Likert de 0 a 4 pontos, agrupados em quatro fatores: reações físicas, reações psicológica, reações psicológicas com componente depressivo e reações psicofisiológicas. Pontuações menores que 39,60 pontos, indicam a não existência de sintomas de estresse; de 39,60 a 59,50 pontos, o sujeito encontra-se na fase de alerta; de 59,50 e 79,40 pontos, tem-se a fase de resistência; de 79,40 e 99,30 pontos, tem-se a fase de quase-exaustão e, pontuação total acima de 99,30 pontos na escala, o sujeito encontra-se na fase de exaustão.

3. Ryoduraku: aparelho com função de diagnóstico e de eletro-estimulação dos acupontos. Permite a mensuração energética dos acupontos avaliados bilateralmente no corpo. Após a coleta dos valores, são gerados gráficos indicativos de quadros de excesso ou deficiência nos canais de energia (Hugentobler, 2006; Imamura, 1996).

4. Pastilhas de silício (stipers), representada por uma pastilha de quartzo micronizado de Óxido de Silício, cujas micropartículas são organizadas em uma manta hipoalergênica, que possui $13 \mathrm{~mm}$ de diâmetro e três $\mathrm{mm}$ de espessura. Burigo \& Silvério-Lopes (2010) argumentam que tal material tem seu efeito comparado ao da agulha, com a vantagem de não ser invasivo. O stiper é um material reconhecido pelo organismo e tem a função de ordenar as suas ondas e frequências, pois uma grande porcentagem da constituição orgânica humana é formada por silício.

5. Esferas de cristal, com cerca de um milímetro e, quando afixadas no pavilhão auricular mediante o uso do micropore, servem para a estimulação dos acupontos na orelha. Possuem a vantagem de ficar afixadas nos pontos por mais tempo, de cinco a dez dias.

\section{Procedimento}

Todas as etapas foram realizadas no âmbito da Clínica de Psicologia da UFU. Inicialmente, se procedeu à anamnese com os responsáveis, contendo, além do histórico de saúde das crianças, questões relativas ao estado emocional e ao estresse, do tipo se a criança dorme sozinha, se tem medo, insônia e sudorese, bem como questões abertas sobre o que mais lhe chamava atenção no comportamento da criança. Logo após foi aplicada a Escala de Stress Infantil, visando à avaliação da sintomatologia de estresse nas crianças participantes. A partir dos resultados da escala identificou-se a fase de estresse correspondente, de acordo com os critérios apresentados por Lipp e Lucarelli (2005).

$\mathrm{Na}$ etapa seguinte deu-se início à intervenção com acupuntura, que consistiu em duas sessões semanais de cinquenta minutos cada, durante seis semanas, totalizando doze atendimentos para cada criança participante. Vale observar que algumas crianças faltaram em uma ou outra sessão semanal, contudo foram realizadas todas as sessões.

A partir dos pontos descritos na literatura, em especial nas pesquisas de Cabioglu et al. (2007) e Silva (2010), acerca do tratamento da ansiedade e estresse, foram utilizados no presente estudo os seguintes pontos: F3, VC15, C7, Pe7, P7, R3, TA5, IG4, IG11, BP3, BP6, E36, VC12 e VC6. Para evitar a estimulação de muitos pontos no corpo da criança optou-se por 
organizar os pontos em grupos, contendo de três a quatro acupontos por sessão. Esse procedimento pode minimizar e/ou prevenir o estresse da própria sessão de acupuntura, embora tenha sido utilizado o stiper, cuja fixação é totalmente indolor e inibe uma superestimulação do organismo.

Assim, realizou-se o revezamento dos pontos, utilizando-se na primeira sessão os pontos $\mathrm{F} 3$, VC15, C7, R3; na segunda os pontos IG4, BP3, E36, VC6; na terceira os pontos Pe7, P7, TA5; na quarta os pontos IG11, BP6, VC12, E36, e assim sucessivamente, até a última sessão. Para uma melhor compreensão da localização dos pontos, ver Pereira (2001).

Além dos pontos acima citados, ressalta-se que também foram utilizados outros pontos diferentes em cada sessão, de acordo com o padrão de desequilíbrio energético observado em cada criança por meio da avaliação do aparelho Ryodoraku. Isso permitiu que cada atendimento fosse único, apesar do uso dos protocolos para estresse identificados na literatura, o que reafirma a importância de um acurado diagnóstico energético para a efetivação da intervenção (Auteroche \& Navailh, 1992).

Antes de cada sessão a pesquisadora, por meio de questões abertas, inquiriu os participantes e seus responsáveis sobre o estado geral de saúde da criança e sua reação ao tratamento efetivado na sessão anterior. Em seguida as crianças foram avaliadas por meio do Ryodoraku. De posse dessas informações e do protocolo anteriormente definido para o tratamento do estresse, procedia-se à estimulação dos acupontos com a colocação das pastilhas de silício, afixadas com micropore, que deviam permanecer de três a quatro dias.

Ao término dessa etapa da pesquisa, com vistas a verificar a existência ou não de alteração na intensidade da sintomatologia apresentada pelas crianças, utilizou-se um questionário no qual os pais informaram sobre os comportamentos observados em seus filhos após a intervenção. Além disso, a Escala de Stress Infantil (ESI) foi reaplicada, com o objetivo de verificar se houve ou não alterações psicológicas no que diz respeito ao estresse.

\section{RESULTADOS}

Participaram do estudo seis crianças, sendo três meninas e três meninos; duas estavam com seis anos e quatro com sete anos. Com relação à escolaridade, uma criança cursava o primeiro ano do ensino fundamental e cinco crianças o segundo ano do ensino fundamental. Os resultados foram obtidos pela aplicação da Escala de Stress Infantil antes e imediatamente após a última sessão de intervenção com a acupuntura. Os dados oriundos das sessões de acupuntura permitiram avaliar os pontos utilizados com maior frequência, além de identificar os meridianos mais acometidos em situações de estresse, relacionando-os com as características dos Cinco Elementos da Medicina Tradicional Chinesa.

Segue abaixo uma breve descrição de cada criança.

Criança 1: menino de seis anos cursando o $2^{\circ}$ ano do ensino fundamental no período da manhã. Reside com a mãe, que informou que a gestação não teve complicações e o parto foi cesariano. A criança faz amizades com facilidade. A mãe acredita que o filho é estressado porque rói as unhas, dá risadas muito altas, tem agitação motora e repete muito a mesma coisa. A criança apresenta muito medo de dormir sozinha. Na Escala de Stress Infantil obteve 70 pontos antes do procedimento, o que indica fase de resistência ao estresse, e 59 pontos após a intervenção, o que indica fase de alerta ao estresse. Após a intervenção foi relatado que a criança parou de roer as unhas e diminuiu as manifestações de medo.

Criança 2: menino de sete anos cursando o $2^{\circ}$ ano do ensino fundamental no período da tarde. Reside com a família. A mãe informou que a gestação não teve complicações e o parto foi cesariano. $\mathrm{O}$ menino faz amizades com facilidade. A mãe acredita que ele é estressado porque é inquieto, disperso e irritado. Acrescenta que a criança sempre volta da escola com machucados, devido à sua agitação durante o recreio. $\mathrm{Na}$ Escala de Stress Infantil obteve 70 pontos antes do procedimento, o que indica fase de resistência ao estresse, e 57 pontos após a intervenção, o que indica fase de alerta ao estresse. Após a intervenção foi relatado que a criança demonstrou estar mais calma e tranquila. Além disso, a professora do menino comentou aos pais que ele está mais calmo e concentrado em sala de aula.

Criança 3: menina de sete anos cursando o $2^{\circ}$ ano do ensino fundamental no período da tarde. Reside com a família. Segundo relato da mãe, a gestação não teve complicações e o parto foi cesariano. Não faz amizade com facilidade. A mãe acredita que a filha é estressada porque tem o hábito de comer compulsivamente, chorar muito e ficar trancada no quarto quando suas vontades são contrariadas, além de ter insônia. Na Escala de Stress Infantil obteve 83 pontos antes do procedimento e 81 pontos após a intervenção, o que indica fase de quase exaustão ao estresse. Após 
a intervenção houve relatos de que a criança demonstrou estar mais tranquila e sem episódios de insônia.

Criança 4: menina de sete anos cursando o $2^{\circ}$ ano do ensino fundamental no período da tarde. Reside com a família. Segundo relato da mãe, a gestação não teve complicações e o parto foi cesariano. Faz amizade com facilidade. A mãe acredita que a criança é estressada porque come compulsivamente, chora muito, briga com os primos e com o irmão e fica apreensiva quando não entende as tarefas. Na Escala de Stress Infantil obteve 79 pontos antes do procedimento, o que indica fase de resistência ao estresse, e 54 pontos após a intervenção, o que indica fase de alerta ao estresse. Após a intervenção foi relatado que a criança demonstrou estar menos ansiosa, mais tranquila e mais obediente. A professora da criança comentou com a mãe que a menina parecia estar mais calma, com diminuição do comportamento de choro, além de estar acompanhando com mais facilidade o ritmo da turma.

Criança 5: menino de seis anos cursando o $1^{\circ}$ ano do ensino fundamental no período da tarde. Reside com a família. Segundo relato da mãe, a gestação não teve complicações. O parto foi normal e a criança nasceu com o cordão umbilical enrolado ao pescoço, mas sem maiores complicações. A criança faz amizades com facilidade. A mãe acredita que o menino é estressado porque é inquieto, pula incessantemente de um lado para o outro em casa. $\mathrm{O}$ menino apresenta dificuldades na fala, pronunciando as palavras de forma errada, o que torna difícil a sua compreensão e contribui para que ele fique nervoso. Na Escala de Stress Infantil obteve 50 pontos antes do procedimento e 52 pontos após a intervenção, o que indica fase de alerta ao estresse. Após a intervenção foi relatado que a criança diminuiu a agitação motora e o aparente nervosismo expresso em seus comportamentos.

Criança 6: menina de sete anos cursando o $2^{\circ}$ ano do ensino fundamental no período da tarde. Reside com a família. Segundo relato da mãe, a gestação não teve complicações e o parto foi cesariano. Demonstra ser tímida, mas tem amigos. Apresenta dificuldade em ler e escrever e, segundo os pais, ela sabe somente copiar as palavras, mas não sabe ler o que está escrito. A mãe acredita que a criança é estressada porque não consegue esperar por algo que deseja muito e se alimenta compulsivamente nesses momentos. Na Escala de Stress Infantil obteve 41 pontos antes do procedimento e 58 pontos após a intervenção, o que indica fase de alerta ao estresse. Após a intervenção foi relatado que a criança estava mais tranquila.

Os dados das crianças podem ser observados na Figura 1.

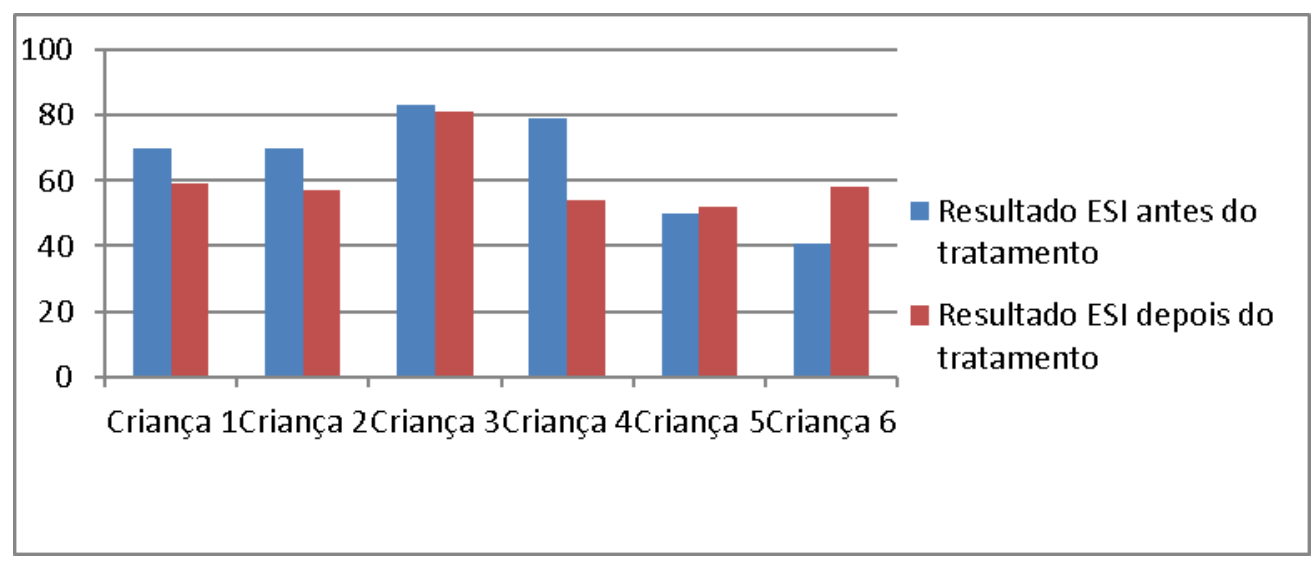

Figura 1. Resultado da Escala de Stress Infantil de cada criança.

Considerando o resultado obtido na Escala de Stress Infantil, três crianças mantiveram o mesmo nível de estresse antes e depois da intervenção, o que pode ser explicado pela necessidade de um número maior de sessões e também pelo fato de que durante o tratamento ocorreram episódios potencialmente estressantes, como provas escolares, morte de parente e doença de familiares, o que interfere na forma como a criança responde ao instrumento.

Contudo, a despeito dos resultados obtidos na escala, os relatos dos genitores enfatizaram que, após a intervenção com a acupuntura, seus filhos estavam mais calmos e tranquilos tanto em casa como na escola, manifestando menos os sintomas de roer unhas, inquie- 
tação, insônia e medo, o que se constitui num achado merecedor de uma investigação mais acurada, tanto pela necessidade de instrumentos mais precisos em relação à avaliação do estresse infantil quanto pela possibilidade do efeito placebo, que não pode ser desconsiderada.
Por outro lado, a partir dos dados gerados pelo Ryodoraku no primeiro e no último dia da intervenção, observou-se que alguns pontos se repetiam durante algumas sessões. Ao analisar o número de pontos utilizados em cada meridiano, obtiveram-se os dados observados na Figura 2.

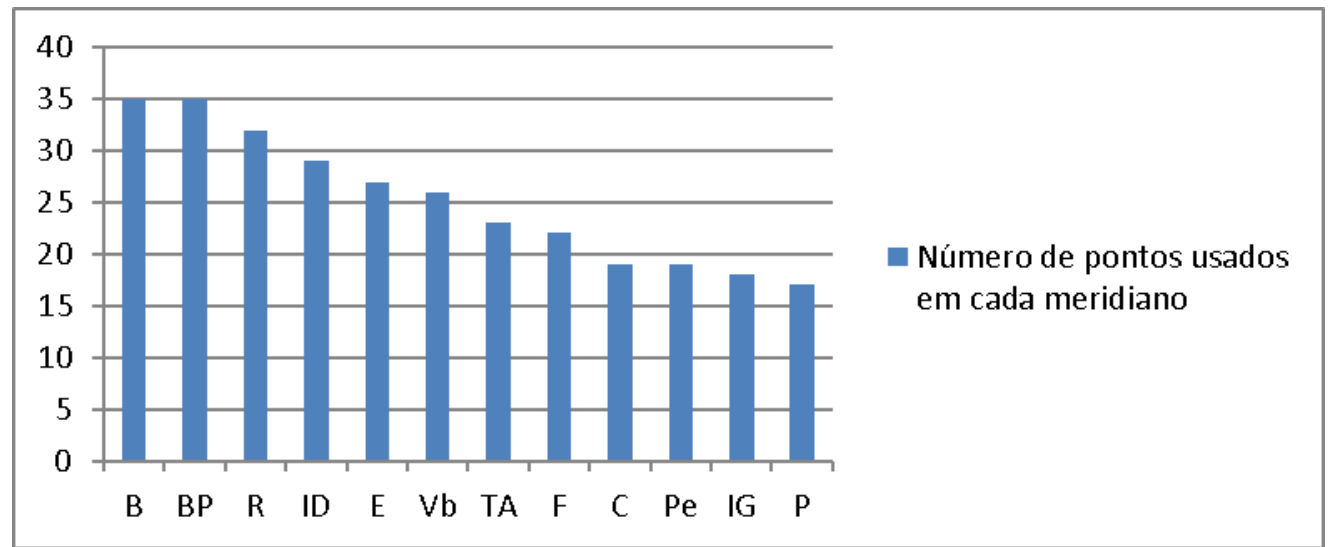

Figura 2. Quantidade de pontos utilizados em cada meridiano, conforme avaliação Ryodoraku.

Desse modo, a Figura 2 evidencia que os pontos mais utilizados correspondem aos meridianos da Bexiga (B) e do Baço-Pâncreas (BP) que, por sua vez, identificam os elementos mais sujeitos a desequilíbrios, considerando a patologia avaliada.
Assim, ao analisar a quantidade de vezes em que os pontos de um mesmo elemento foram usados, obteve-se o resultado explicitado na Figura 3.

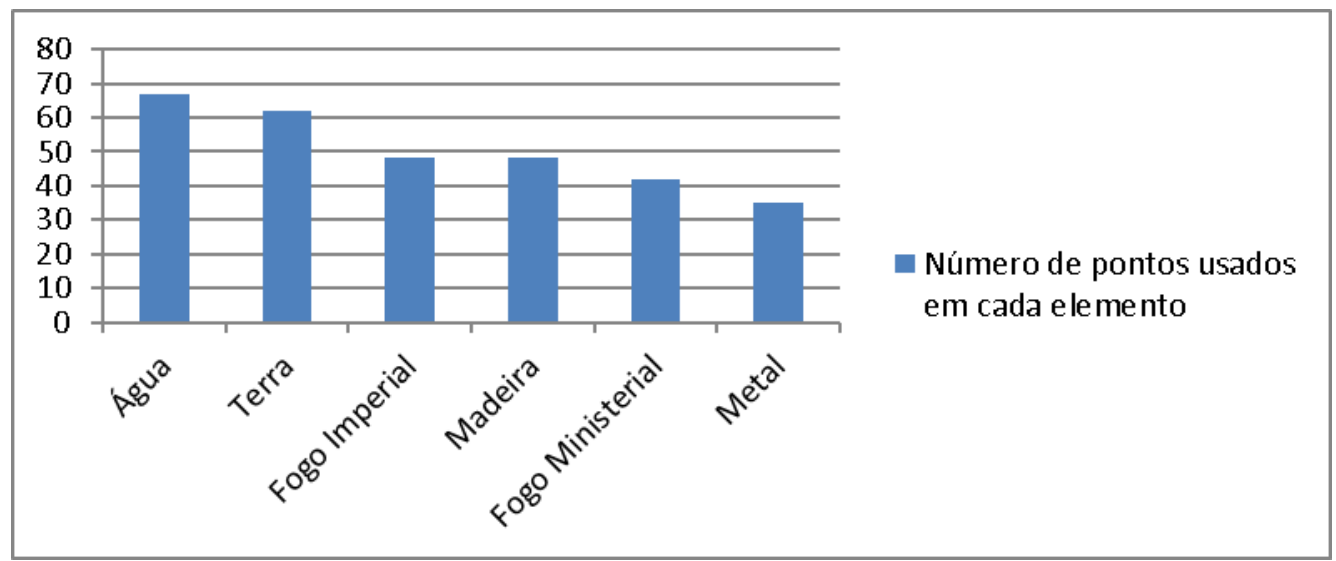

Figura 3. Número de pontos usados em cada elemento.

Avaliando os elementos que foram usados com mais frequência, o que denota que esses possuíam maior desarmonia energética, os mais expressivos foram Água e Terra. Segundo a Medicina Tradicional Chinesa (MTC), o elemento Água se relaciona à emo- ção do medo, que foi um indicador frequente no relato das crianças participantes. Já a desarmonia do elemento Terra se relaciona à preocupação, que também estava presente nos comportamentos e relatos das crianças. Por outro lado, o elemento menos usado foi Me- 
tal, o qual se manifesta pela emoção de tristeza, parecendo exercer menor influência em casos de estresse.

A Figura 4 mostra que as crianças tenderam a uma harmonização do nível energético que é, em última análise, o objetivo da acupuntura. Segundo a avaliação do aparelho Ryodoraku, há uma diferença entre os excessos de energia (valor mais alto obtido na verificação dos pontos) e as deficiências de energia (valor mais baixo obtido na verificação dos pontos), que se reduziram após a intervenção. Esclarece-se que o valor médio das energias antes e depois do tratamento é obtido comparando-se graficamente as leituras digitais dos 12 acupontos, representados por P9, CS7, C7, ID5, TA4, IG5, BP3, F3, R4, B65, VB40 e E42 e que se encontram enumerados em uma tabela. Segundo Breves (s/d), "constatou-se que as pessoas clinicamente saudáveis possuem os valores dos seus ' 24 meridianos' (12 acupontos localizados nos meridianos do lado esquerdo e 12 acupontos localizados nos meridianos do lado direito do corpo) comprimidos numa faixa horizontal de $1,4 \mathrm{~cm} "$.

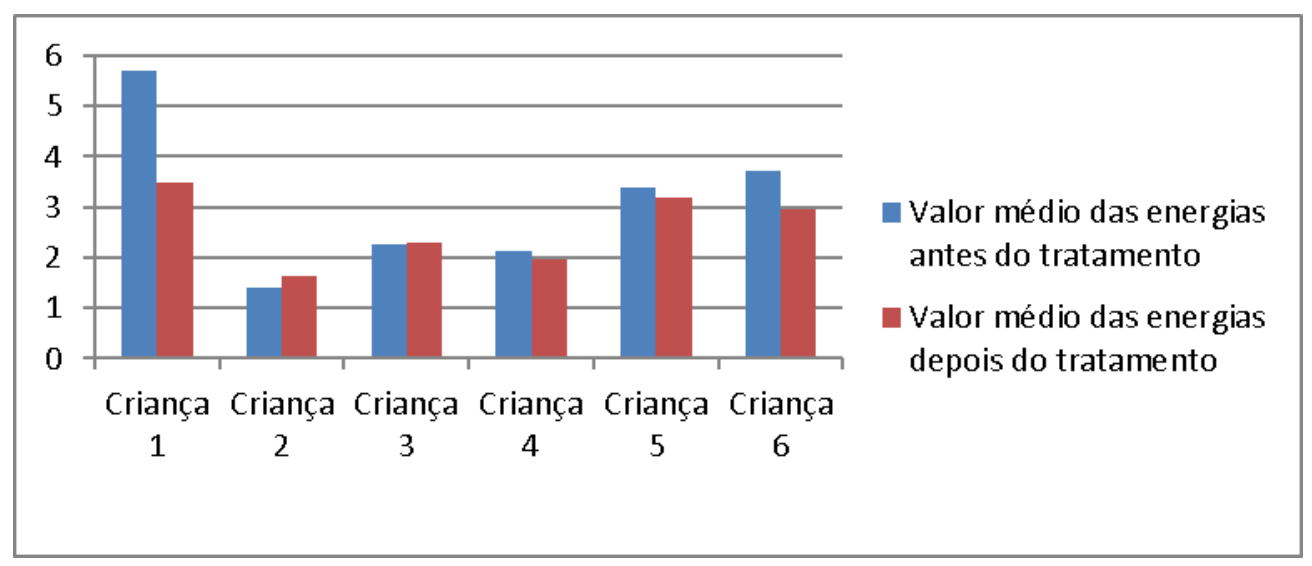

Figura 4. Comparação entre o valor médio das energias de cada criança.

\section{DISCUSSÃO}

Avaliar a intervenção, por meio da prática da acupuntura, junto às crianças com sintomas de estresse foi um dos objetivos perseguidos por este estudo que, a despeito de suas modestas proporções, lançou luz sobre alguns aspectos que estão presentes quando se depara com a complexidade dessas variáveis.

Quais fatores são considerados desencadeadores de estresse nessas crianças? Quais sintomas manifestados pela criança indicam sofrimento mental? Como a criança lida com esse sofrimento? Qual é a atuação da família? Em quais aspectos a acupuntura pode ajudar? As respostas a essas questões foram alguns dos desafios presentes em todas as etapas do estudo e nortearam a busca pela resposta ao objetivo principal que foi o de "conhecer e avaliar a adequação do uso da acupuntura na sintomatologia de estresse nas crianças, antes e após a intervenção com acupuntura".

No que concerne aos fatores emocionais, observou-se a presença de problemas financeiros da famí- lia, problemas de saúde com constantes visitas ao hospital, mudança de casa, morte de parente, brigas dentro de casa, início da vida acadêmica e nascimento de irmãos como situações desencadeadoras de estresse nas crianças participantes da presente pesquisa e que estão descritos na literatura (Asbahr, 2004; Friedberg \& McClure, 2004; Lipp \& Lucarelli, 2005).

Em acréscimo, foi possível evidenciar sintomas como medo de dormir sozinha, insônia, sudorese, agitação, falta de paciência, hábito de roer unhas e mastigar lápis, insegurança, tiques, irritação, compulsão alimentar, intolerância à frustração, apreensão, dor abdominal sem origem física aparente, nervosismo, hábito de ranger os dentes e de carregar consigo algum brinquedo o tempo todo, preocupação com coisas ruins e enurese, corroborando com o exposto pelos autores anteriormente mencionados.

Outro fator de destaque refere-se modo como a criança lida com o seu sofrimento. Elas relatam se utilizar de alguns recursos para tentar aliviar o estresse, como assistir desenhos na TV, sentar na cama e ficar 
quieto por 30 minutos, roer unha, comer com frequência e chorar. A esse conjunto de estratégias elaboradas na tentativa de lidar com as situações desencadeantes de estresse dá se o nome de coping (ou enfrentamento).

Antoniazzi, Dell' Aglio e Bandeira (1998) citam o modelo criado na década de 1980, elaborado por Lazarus e Folkman, no qual o coping resulta em esforços cognitivos e comportamentais sentidos e emitidos pela pessoa na tentativa de minimizar os fatores ambientais estressantes e ansiogênicos. Dell'Aglio e Hutz (2002) mencionam algumas características do coping, que foram identificados nas crianças participantes, como a inação (não ter iniciativa de superação), a presença de atividade de autocontrole, comportamento de evitação e distração, atividades de isolamento e expressão emocional.

Diante desse contexto, é importante considerar a atuação da família perante as dificuldades dos filhos. No presente estudo foi possível constatar atitudes que vão de elogios e carinhos feitos à criança até comportamentos desistentes e derrotistas por parte dos pais, conforme evidenciado nas declarações "eu acabo fazendo o que ela pede, cedo à pressão para ela parar de chorar"; "eu não consigo controlar minha filha, ela é incontrolável". A presença atuante dos pais demonstra a presença de apoio social característica do coping (Dell'Aglio \& Hutz, 2002).

Assim, é possível dizer que o estresse se configura num estado gerador de desequilíbrio que envolve o ser em toda a sua abrangência, tanto no que se refere aos aspectos orgânicos quanto nos mais sutis, determinados pela subjetividade humana. Nesse aspecto, os dados apresentados sugerem que a acupuntura pode ser um recurso pertinente em intervenções visando à promoção da saúde física e mental das crianças, e se hipotetiza que os efeitos da acupuntura possam ser potencializadas quando agregada a outras técnicas ou abordagens psicoterápicas.

Vale destacar que as pastilhas de silício, usadas em substituição às agulhas, demonstraram ser adequadas aos propósitos do estudo, com a vantagem de ser um material indolor, não invasivo e fornecer estimulação mesmo após o término das sessões. Por possuir tais características, observou-se grande receptividade, comprometimento e adesão ao tratamento, tanto por parte das crianças quanto de seus familiares.

\section{CONSIDERAÇÕES FINAIS}

Compreender o uso da acupuntura em fenômenos de estresse infantil foi o propósito maior desse estudo. Embora o número de participantes não se constitua numa amostra significativa em termos estatísticos e, portanto, não permita generalizações, pode-se dizer que a acupuntura pode constituir um efetivo recurso disponível ao profissional no manejo de quadros indicativos de estresse em crianças. Em acréscimo, foi possível constatar que o uso da acupuntura nessa amostra mostrou-se eficiente para harmonizar o nível energético das crianças.

É importante registrar que, além do Ryodoraku, que foi o instrumento escolhido para diagnosticar energeticamente e tratar as crianças participantes, por ser mais objetivo, no sentido de mensurável, há outras formas de fazer o diagnóstico e o tratamento pela acupuntura, como avaliação pelos microssistemas (orelha, língua), Escola dos Cinco Elementos ou Movimentos, dentre outros. Para mais informações, consultar Campiglia (2004), Hicks et al. (2007) e Maciocia (2007b).

O presente trabalho lançou luzes sobre a importância da acupuntura em quadros que envolvem sofrimento mental, devendo, portanto, cada vez mais suscitar estudos, de maneira a permitir a avaliação cada vez mais acurada da técnica. Com base nos resultados obtidos nesta pesquisa, verificou-se a importância que a acupuntura teve na vida das crianças participantes. Entretanto, apesar da presente pesquisa ter contribuído para ampliar os conhecimentos acerca do uso da acupuntura em patologias infantis, ainda há muito a ser pesquisado principalmente no que diz respeito ao estresse na infância, devido à sua potencialidade deletéria para a saúde humana. Esta, conforme preconizado pela Organização Mundial de Saúde, representa um "estado de completo bem-estar físico, mental e social, e não apenas a ausência de doenças".

A prática da acupuntura em crianças é praticamente inexistente no contexto brasileiro, em especial, atrelado a alguma forma de intervenção psicoterápica, pelo menos no que concerne à efetivação e divulgação de achados científicos, constituindo-se assim num amplo campo de estudos tanto para os profissionais de psicologia, quanto de áreas afins, que tem na indissociabilidade entre o corpo e a mente, o seu propósito maior. Por fim, espera-se que este estudo tenha cumprido com o seu papel de colaborar para o avanço da ciência, de maneira que haja uma maior sensibilização e busca de ações efetivas que permitam que essas crianças sejam saudáveis e felizes, aptas para viver numa sociedade mais plural e harmônica. 


\section{REFERÊNCIAS}

American Psychiatric Association. (2002). Manual diagnóstico e estatístico de transtornos mentais - DSM-IV-TR. (C. Dornelles, trad.). ( $4^{\mathrm{a}}$.ed.). Porto Alegre, RS: Artmed.

Antoniazzi, A. S., Dell'Aglio, D. D., \& Bandeira, D. R. (1998). O conceito de coping: Uma revisão teórica. Estudos de Psicologia, 3 (2), 273-294. Retirado de http://www.scielo.br/pdf/\%0D/ epsic/v3n2/a06v03n2.pdf em 09 de fevereiro de 2012.

Asbahr, F.R. (2004). Transtornos ansiosos na infância e adolescência: Aspectos clínicos e neurobiológicos. Jornal de Pediatria, 80 (2) [Supl], S28-S34. Retirado de http://www.scielo.br/ pdf/jped/v80n2s0/v80n2Sa05.pdf em 30 de setembro de 2010.

Assis, S. G., Ximenes, L. F., Avanci, J. Q., \& Pesce, R. P. (2007). Ansiedade em crianças: Um olhar sobre transtornos de ansiedade e violências na infância. Rio de Janeiro: FIOCRUZ/ ENSP/CLAVES/CNPq.

Assumpção Jr., F. B., \& Rech, C. R. (2006). Escala de avaliação da ansiedade-traço infantil: Um estudo de sensibilidade e especificidade. Arquivos brasileiros de Psiquiatria, Neurologia e Medicina Legal, 100(1), 19-25. Retirado de http://www.aperj rio.org.br/publicacoes/revista/2006/jan/P19-25.pdf em 28 de outubro de 2010 .

Auteroche, B. \& Navailh, P. (1992). O diagnóstico na medicina chinesa. São Paulo: Andrei.

Breves, R. (s/d). Manual Acuspointer. Retirado de http://www. medichina.com.br/arquivos/acuspointer_manualx 1a.pdf em 23 de abril de 2013.

Burigo, F. L., \& Silvério-Lopes, S. (2010). Lombalgia crônica mecânica: Estudo comparativo entre acupuntura sistêmica e pastilhas de óxido de silício (stimulation and permanency - stiper). Revista Brasileira de Terapias e Saúde, 1 (1), 27-36. Retirado de http://omnipax.com.br/ojs/index.php/RBTS/article/ view/3/11 em 18 de fevereiro de 2011.

Cabioglu, M. T., Ergene, N., \& Tan, Ü. (2007). Electroacupunture treatment of obesity with psychological symptoms. International Journal of Neuroscience, 117 (5), 579-590. Retirado de http://informahealthcare.com/doi/abs/10.1080/0020745050053 5545 em julho de 2010.

Campiglia, H. (2004). Psique e medicina tradicional chinesa. São Paulo: Roca.

Dell'Aglio, D. D., \& Hutz, C. S. (2002). Estratégias de coping de crianças e adolescentes em eventos estressantes com pares e com adultos. Psicologia USP, 13(2). Retirado de http:// www.scielo.br/scielo.php?script=sci_arttext\&pid=S010365642002000200012 em 09 de fevereiro de 2012.

Doria, M. C.da S. (2010). Eficácia do tratamento de acupuntura na sintomatologia do stress. Dissertação de Mestrado, Programa de Pós-Graduação Stricto Sensu em Psicologia, PUC Campinas. Campinas.

Doria, M. C.da S., Lipp, M. E.N., \& Silva, D. F. (2012). O uso da Acupuntura na sintomatologia do stress. Psicologia: Ciência e Profissão, 32(1), 34-51.
Evans, N. E. (2012). Acupuncture for Anxiety. CNS Neuroscience \& Therapeutics, 18, 277-284.

Farrow, C., Haycraft, E., \& Meyer, C. (2009). Similarities between eating atitudes among friendship groups. Journal of Pediatric Psychology, 1-9. Retirado de http://www.jpepsy.oxford journals.org em 27 de setembro de 2010.

Friedberg, R. D., \& McClure, J. M. (2004). Prática clínica de terapia cognitiva com crianças e adolescentes. Porto Alegre: Artmed.

Gold, J. I., Nicolaou, C. D., Belmont, K. A., Katz, A. R., Benaron, D. M., \& Yu, W. (2009). Pediatric Acupuncture: A Review of Clinical Research. Evidence-Based Complementry and Alternative Medicine, 6(4), 429-439.

Gori, L., \& Firenzuoli, F. (2007). Ear acupuncture in european traditional medicine. $e C A M, 4(\mathrm{~S} 1)$, 13-16. Retirado de http://ecam.oxfordjournals.org em 28 de julho de 2010.

Hicks, A., Hicks, J., \& Mole, P. (2007). Acupuntura constitucional dos cinco elementos. São Paulo: Roca.

Horta, L. (2007). Estresse Infantil: um estudo exploratório com pré-escolares. Dissertação de Mestrado, Programa de PósGraduação em Psicologia Aplicada, Universidade Federal do Uberlândia. Uberlândia.

Hugentobler, D. R. H. (2006). O uso do Ryodoraku no diagnóstico e tratamento energético. Monografia de Especialização, Especialização em Acupuntura, Centro Integrado de Estudo e Pesquisa do Homem. Porto Alegre.

Imamura, S. T. (1996). Eletroacupuntura Ryodoraku. São Paulo: Sarvier.

Jayasuriya, A. (1995). As bases científicas da acupuntura. Rio de Janeiro: Sohaku-In Edições.

Jindal, V., Ge, A., \& Mansky, P. J. (2008). Safety and efficacy of acupuncture in children: A review of the evidence. Journal of Pediatric Hematology/Oncology, 30(6), 431-442. Retirado de http://www.ncbi.nlm.nih.gov/pmc/articles/pmc2518962/ em 15 de abril de 2013.

Lipp, M. E. N. (2000). Manual do Inventário de Sintomas de Stress em Adultos. São Paulo: Casa do Psicólogo.

Lipp, M. E. N., \& Lucarelli, M. D. M. (2005). Escala de Stress Infantil: ESI: manual. Itatiba: Casa do Psicólogo.

Lovibond, P. F., \& Lovibond, S. H. (1995). The structure of negative emotional states: Comparison of the Depression Anxiety Stress Scales (DASS) with the Beck Depression and Anxiety Inventories. Behaviour Research and Therapy, 33(3), 335-343. Retirado de http://www.sciencedirect.com/science/article/pii/ 000579679400075 U em 14 de outubro de 2011.

Maciocia, G. (2007a). Canais de acupuntura: Uso clínico dos canais secundários e dos oito vasos extraordinários. São Paulo: Roca.

Maciocia, G. (2007b). Os fundamentos da medicina chinesa: Um texto abrangente para acupunturistas e fitoterapeutas. São Paulo: Roca. 
Muzzolon, S. R. B. (2008). Avaliação do uso da lista de sintomas pediátricos como instrumento para a triagem de problemas emocionais e psicossociais em uma escola pública de Curitiba. Dissertação de Mestrado, Programa de Pós-Graduação em Saúde da Criança e do Adolescente, Universidade Federal do Paraná. Curitiba.

Pais-Ribeiro, J. L., Honrado, A., \& Leal, I. (2004). Contribuição para o estudo da adaptação portuguesa das Escalas de Ansiedade, Depressão e Stress (EADS) de 21 itens de Lovibond e Lovibond. Psicologia, Saúde e Doenças, 5(2), 229-239. Retirado de http://www.scielo.oces.mctes.pt/pdf/psd/v5n2/v5n2a07.pdf em 27 de julho de 2011.

Pereira, F. A. O. (2001). Localização dos pontos de acupuntura. Rio de Janeiro: Sohaku-In Edições.

Ross, J. (2003). Combinações dos pontos de acupuntura: A chave para o êxito clínico. São Paulo: Roca.

Silva, A. L. P. da. (2010). O tratamento da ansiedade por intermédio da acupuntura: Um estudo de caso. Psicologia Ciência e Profissão, 30 (1), 200-211. Retirado de http://pepsic.bvsalud. org/pdf/pcp/v30n1/v30n1a15.pdf em 25 de novembro de 2010.

Silva, W. V., \& Figueiredo, V. L. M. (2005). Ansiedade infantil e instrumentos de avaliação: Uma revisão sistemática. Revista Brasileira de Psiquiatria, 27(4), 329-335. Retirado de http://www.scielo.br/pdf/rbp/v27n4/a14v27n4.pdf em 30 de setembro de 2010.
Simmons, R. (2000). Estresse: Esclarecendo suas dúvidas. São Paulo: Agora.

Spence, A. P. (1991). Anatomia humana básica. (2ª ed.). Barueri: Manole.

Van de Graaff, K. M. (2003). Anatomia humana. (6 ${ }^{\mathrm{a}}$ ed.). Barueri: Manole.

Vectore, C. (2005). Psicologia e acupuntura: Primeiras aproximações. Psicologia Ciência e Profissão, 25(2), 266-285. Retirado de http://pepsic.bvsalud.org/pdf/pcp/v25n2/v25n2a09.pdf em 03 de junho de 2009.

Yamamura, Y. (1993). Acupuntura tradicional: A arte de inserir. São Paulo: Roca.

Zumstein, L. S. (2009). Recursos mediacionais: Possibilidades de utilização para identificação de estressores em pré-escolares. Dissertação de Mestrado, Programa de Pós-Graduação em Psicologia, Universidade Federal de Uberlândia. Uberlândia. 